\title{
Epidemiological Updates of Zika Transmission and Emphasizing the Critical Role of Public Health Interventions
}

\author{
Article by Soosanna Kumary ${ }^{1}$, Vijay Kumar Chattu ${ }^{2}$ \\ ${ }^{1}$ Researcher-Department of Preclinical sciences, Faculty of Medical Sciences, UWI- \\ St. Augustine \\ ${ }^{2}$ Lecturer-Public Health, Public Health and Primary Care Unit, FMS, UWI- Trinidad \\ and Tobago \\ E-mail: susanna.poul@gmail.com
}

\begin{abstract}
Since the start of Zika epidemic this year, till date there are more than 45 countries with active Zika virus transmission. Considering its spread at an alarming rate with large clusters of microcephaly and neurological complications, the Emergency Committee of the World Health Organization (WHO) under the International Health Regulations (IHR) announced that Zika constitutes Public Health Emergency of International Concern (PHEIC) on February 1, 2016. Countries in Central America and South America show a decreasing trend of cases where as there is an increasing number of cases in USA and some Caribbean states. Recently after careful review of the existing evidence the scientists at CDC concluded that Zika virus causes Microcephaly a condition in which the size of baby's brain and head is smaller than the normally expected. For planning more effective disease control and prevention activities for Zika fever there is great need for a functional and intensified Public Health Surveillance system Preparedness for the prevention and control of Zika virus infection. Risk communications should be enhanced in countries with Zika virus transmission to address population concerns, enhance community engagement, improve reporting, and ensure application of vector control and personal protective measures. Vector control measures and appropriate personal protective measures should be aggressively promoted and implemented to reduce the risk of exposure to Zika virus. Attention should be given to women of childbearing age and particularly pregnant women so that they have the necessary information and materials to reduce risk of exposure
\end{abstract}

Keywords: Zika virus, Public Health Emergency of International Concern, International Health Regulations, Guillain-Barre Syndrome, Microcephaly, Vector control

\section{Introduction}

Zika virus is a member of the Flaviviridae family (which includes Dengue, West-Nile and Japanese encephalitis viruses) transmitted to humans by Aedes mosquitoes and produces a comparatively mild disease in humans but confirmed to cross the placenta of pregnant women and affect the foetus makes it very unique from other Arboviruses [1]. It is considered an emerging infectious disease with the potential to spread to new areas where the Aedes mosquito vector is present and have already spread to 45 countries through autochthonous transmission since its recent emergence in 2015. The highly suspected association between microcephaly and the rapid increase in Zika cases during the current outbreak has contributed to the virus' notoriety and is one of the key reasons behind ongoing global containment efforts [2].Considering its spread at an alarming rate with large clusters of microcephaly and neurological complications, the Emergency Committee of the World Health Organization (WHO) under the International Health Regulations (IHR) announced that Zika constitutes Public Health Emergency of International Concern (PHEIC) on February 1, 2016[3].WHO has warned that a warming weather throughout Europe and could mean an increased chance of spreading the virus in the region as the two species of Aedes mosquito which transmit the virus will begin to circulate in the community. Apart from the local transmission the 
Texila International Journal of Public Health

Volume 5, Issue 1, Mar 2017

likelihood of sexual transmission could lead to an increase in number of Zika related complications. The eight countries that have reported transmission through sexual contact includes France, Italy and Portugal.

\section{Zika virus- incidence and trends in the americas}

Since the start of Zika epidemic this year, till date there are more than 45 countries with active Zika virus transmission. In the North America, Mexico is showing a downward trend in the number of confirmed cases while in the United States of America, the area of Zika transmission continues to expand in Miami-Dade County and the Florida Department of Health has confirmed an autochthonous case of Zika virus infection [4]. In Central America, with the exception of Costa Rica and Nicaragua, countries in Central America show a decreasing trend of cases over the previous four weeks. The greatest increase in Zika cases in Central America occurred between late 2015 and early 2016.In the Caribbean Saint Barthelemy and Puerto Rico continue to show an increasing trend of Zika cases; however, in other Caribbean countries and territories, the trend is declining. Finally in South America, all countries are reporting decreasing numbers of Zika cases. In the following weeks, it will be necessary to monitor the evolution of the outbreak to confirm whether the declining trend will continue. Canada reported two cases of maternal-fetal transmission of Zika Virus, including one with severe neurological congenital anomalies

To date, 14 countries and territories in the Americas reported congenital syndrome associated with Zika virus. Five additional countries and territories reported confirmed cases of congenital syndrome associated with Zika virus infection: Costa Rica, the Dominican Republic, Haiti, Honduras, and Suriname. Additionally, three countries reported suspected and probable cases of congenital syndrome associated with Zika virus infection: Barbados, Guatemala, and Nicaragua.

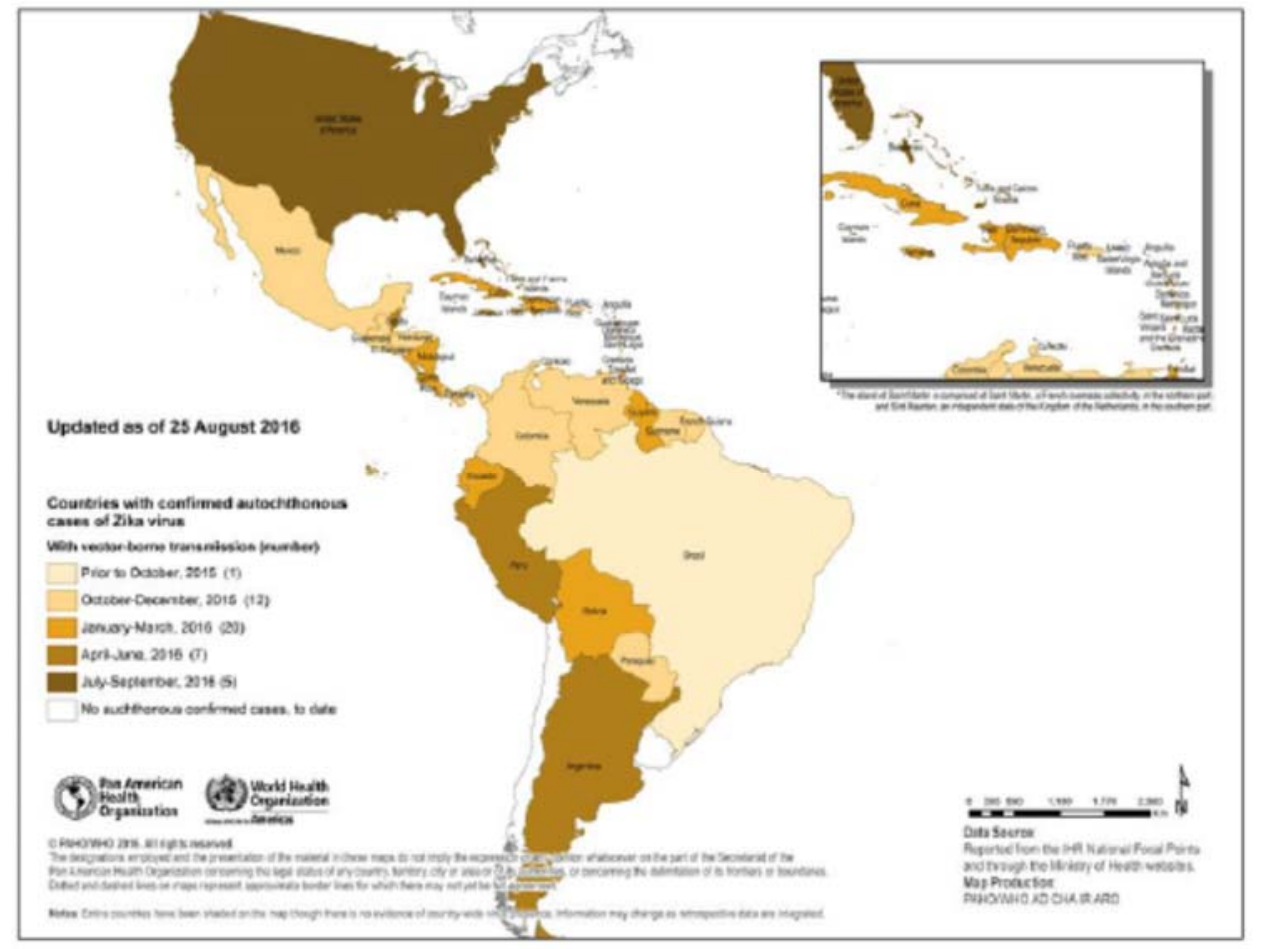

Fig 1. Countries and Territories in the Americas with the confirmed cases of Zika virus (as of 25 August, 2016) source: PAHO/WHO 


\section{Clinical features}

The most common symptoms of Zika include fever, rash, joint pains, conjunctivitis. The illness is mild and symptoms lasts for few days to a week after being bitten by an infected mosquito and many people don't realize that. It is estimated that four out of five people with Zika infection have no symptoms at all [5].

\section{Transmission of virus}

People with asymptomatic infections and those who are viraemic in the incubation period of Zika disease could potentially donate contaminated substances of human origin without their infections being recognised at the time of donation. The virus can also be transmitted by substances of human origin from donors after clinical recovery from Zika virus disease due to possible prolonged viraemia or a persistence of the virus in semen after viraemia has cleared. Zika virus RNA has been detected in blood, urine, saliva, seminal fluid and breast milk but there is no data on the survival of Zika virus in processed and stored substances of human origin as well as no documented transmissions of the virus via saliva, urine or breastfeeding [6-17]. Cases of Zika virus transmission through donated cells, tissues and organs have not been reported, but this possibility cannot be excluded due to the confirmed presence of the virus in human blood and bodily fluids.

\section{Neurological complications}

The recent Zika virus infection (Zika) epidemic in Brazil has been associated with neurological anomalies, including an increase in the number of cases of microcephaly and, more recently, Guillain-Barré syndrome (GBS) $[18,19]$. The correlation between Zika and GBS was first reported in 2013 in French Polynesia [20]. GBS symptoms include weakness of the arms and legs that is usually the same on both sides of the body. In some cases, the muscles of the face that control eye movement or swallowing may also become weak. In the most serious cases, this muscle weakness can affect breathing, and people sometimes need a breathing tube to help them breathe. These symptoms can last a few weeks or several months. Although most people fully recover from GBS, some people have permanent damage, and in 1 out of 20 cases people have died.

\section{Pregnant women and birth defects}

To date, 14 countries and territories in the Americas reported congenital syndrome associated with Zika virus. The foetus can be infected in womb from the pregnant mother and recently after careful review of the existing evidence the scientists at CDC concluded that Zika virus causes Microcephaly a condition in which the size of baby's brain and head is smaller than the normally expected. Apart from that there may be other severe brain defects in the new born baby. This implies that the woman who is infected with Zika during pregnancy has an increased risk of having baby with these problems and not all women who have Zika virus infection during pregnancy will have babies with problems since some infected women have delivered babies that appear to be healthy.

\section{Public health interventions}

Prevention and Control remains the main stay for controlling the number of new cases. There is a great need for the public health authorities to reach the communities and establish good partnerships with all the stakeholders like the community groups, NGOs, private sector including the medical and non-medical professionals to combat the mosquito menace.

\section{Surveillance}

For planning more effective disease control and prevention activities for Zika fever there is great need for a functional and intensified Public Health Surveillance system that can be based on the same system for Dengue and Chikungunya fever. As per the recommendations of PAHO/WHO[21], the surveillance for Zika fever should be focused to 
Texila International Journal of Public Health

Volume 5, Issue 1, Mar 2017

i. Determine if the virus is autochthonous or has been introduced to an area

ii. Monitor the Zika virus in case if its introduced and

iii. Monitor the disease process once it has been established.

iv. Monitor for neurological and autoimmune complications

Considering the broad distribution of Aedes mosquito in the Americas and the high mobility of people in and outside of this region now Zika has spread to the states of Florida and Texas

The Emergency Committee of WHO has emphasized on the following measures which helps to contain the growing epidemic.

- Surveillance for Zika virus infection should be enhanced, with the dissemination of standard case definitions and diagnostics to at-risk areas,

- The development of new diagnostics for Zika virus infection should be prioritized to facilitate surveillance and control measures,

- Risk communications should be enhanced in countries with Zika virus transmission to address population concerns, enhance community engagement, improve reporting, and ensure application of vector control and personal protective measures,

- Vector control measures and appropriate personal protective measures should be aggressively promoted and implemented to reduce the risk of exposure to Zika virus,

- Attention should be given to ensuring women of childbearing age and particularly pregnant women have the necessary information and materials to reduce risk of exposure,

- Pregnant women who have been exposed to Zika virus should be counseled and followed for birth outcomes based on the best available information and national practice and policies.

\section{Longer-term measures}

- Appropriate research and development efforts should be intensified for Zika virus vaccines, therapeutics and diagnostics.

- In areas of known Zika virus transmission health services should be prepared for potential increases in neurological syndromes and/or congenital malformations.

Preventive Recommendations (Adapted from PAHO/WHO guidelines on prevention of Zika virus transmission)

Strategy 1: Reduction of Mosquito density: It can be done through the following actions:

1. Strengthen environmental management

2. Ensure no vector breeding sites in common areas like parks, schools etc. to prevent vector propagation

3. Organize mass sanitation campaigns to sensitize the public about cleanliness

4. By applying risk stratification, identify the places like schools, hospitals, transport terminals and ensure mosquitoes are removed with a radius of 400 meters around these places.

5. In areas with virus, use adulticide treatment by spraying to interrupt transmission

6. Ensure proper monitoring during integrated actions for vector control (larval control and adulticide treatment)

\section{Strategy 2: Interruption of human-vector contact/ Personal prevention measures}

\section{A. Individual protection}

1. Rest under bed nets treated with or without insecticides

2. Appropriate clothing to cover the extremities and exposed areas of skin

3. Use repellents containing DEET, IR3535, Icaridin can be applied to exposed skin or clothing as per the instructions on the product label 


\section{B. Household protection}

1. Use wire-mesh screens on doors and windows

2. At least once a week, empty, clean, turn over or dispose the containers that can hold water such as buckets, flower pots, tires inside and outside of dwellings to eliminate the mosquito breeding sites.

\section{Patient isolation}

1. A Zika virus infected person should avoid being bitten by Aedes mosquitoes during the first week of illness.

2. It is advised to stay under the bed-net and the treating health care workers should also protect from mosquito bites by appropriate measures.

Travel Recommendations (Adapted from PAHO/WHO guidelines on prevention of Zika virus transmission)

\section{i. Prior to departure}

- Travellers heading to a country with circulation of virus are advised to protect themselves from mosquito bites

- Use mosquito repellents, appropriate full sleeve clothing to minimize skin exposure

- Use insecticides or bed-nets treated with or without insecticide

- Sensitize and inform the travellers about the signs and symptoms of Zika/Dengue/ Chikungunya virus in order to identify it promptly and to consult the physician as early as possible during their trip

\section{ii. While visiting places with zika virus transmission:}

- Avoid mosquito-infested areas

- Protect from mosquito bites by appropriate measures by using repellents and appropriate clothing to reduce skin exposure

- Avoid the mosquito bites especially during day time as Aedes bites mostly at night time

- Use of bed-nets and/or insecticide

- Seek professional care in case there are symptoms of Zika/ dengue/ Chikungunya

\section{iii. Upon return}

- Contact the health care provider in case if they suspect they have Zika. Dengue/ Chikungunya after returning home.

The CDC has given the following advice to the pregnant women and the women trying to get pregnant [22]

\section{Pregnant women}

- Should not travel to any area with Zika

- If you must travel to or live in one of these areas, talk to your healthcare provider first and strictly follow personal protection measures like using repellents, covering the exposed skin, using mosquito nets and insecticide sprays.

- If you or your partner live in or travel to an area with Zika, use condoms or other barriers, the right way, every time you have sex or do not have sex throughout the pregnancy.

\section{Women trying to get pregnant}

- Before you or your partner travel, talk to your healthcare provider about your plans to become pregnant and the risk of Zika virus infection.

- You and your partner should strictly follow steps to prevent mosquito bites as described in the personal protection measures. 
Texila International Journal of Public Health

Volume 5, Issue 1, Mar 2017

\section{WHO zika research agenda}

The goal of the WHO Zika Virus Research Agenda is to support the generation of evidence needed to strengthen essential public health guidance and actions to prevent and limit the impact of Zika virus and its complications. The Research Agenda identifies critical areas of research where WHO is uniquely placed to implement or coordinate global activities. Research and evidence are the foundation for sound health policies.

$\mathrm{WHO} / \mathrm{PAHO}$ and other partnering institutions have initiated to design and generate standardized clinical and epidemiological research protocols and questionnaires to address key public health questions. Specifically, data collected using the standardized protocols will be used to refine and update recommendations for prevention of Zika virus spread, surveillance and case definitions for microcephaly, to help understand the spread, severity, spectrum and impact on the community of ZIKV and to guide public health measures, particularly for pregnant women and couples planning a pregnancy.

These protocols have been designed to maximize the likelihood that data and biological samples are systematically collected and shared rapidly in a format that can be easily aggregated, tabulated and analysed across many different settings globally

\section{Conclusions}

Zika virus transmission has become a real global health security threat and it emphasizes again for the great need for strengthening the health systems to have a robust and functional surveillance systems with adequate laboratory and clinical support. The clinical, virologic and epidemiologic data related to the increased rates of microcephaly and/or GBS, and Zika virus transmission, should be rapidly shared with the World Health Organization to facilitate international understanding of the these events, to guide international support for control efforts, and to prioritize further research and product development. There is a great need for public and private partnerships to fight this epidemic through community involvement. The preventive measures for halting mosquito breeding sites and personal protective measures to avoid mosquito bites remains the key strategies for effective prevention at community level through proper implementation of the integrated vector control.

\section{Acknowledgements}

The authors wish to thank the reviewers and editors of E-International Journals of Academics and Scientific Research whose comments and reviews strengthened this work. The authors are also grateful to the authors \& publishers of all those articles from where the literature has been reviewed and discussed.

\section{References}

[1]. Atkinson B, Hearn P, Afrough B, Lumley S, Carter D, Aarons. Emma J, et al. (2016) Detection of Zika virus in semen. Emerg Infect Dis. 22(5). 72.

[2]. Barzon L, Pacenti M, Berto A, Sinigaglia A, Franchin E, Lavezzo E, et al. (2016) Isolation of infectious Zika virus from saliva and prolonged viral RNA shedding in a traveller returning from the Dominican Republic to Italy, January 2016. Euro Surveill. March; 21(10).

[3]. Besnard M, Lastere S, Teissier A, Cao-Lormeau V, Musso D. (2014). Evidence of perinatal transmission of Zika virus, French Polynesia, December 2013 and February 2014. Euro Surveill [Internet]. 2014; 19(13): [pii=20751 p.]. Available from: http://www.eurosurveillance.org/ViewArticle.aspx?ArticleId=20751.

[4]. Centers for Disease Control and Prevention, US Department of Health and Human Services, USA. www.cdc.gov/zika. (Accessed on 26 August 2016)

[5]. Cancian N. (2016) Study confirms that Zika virus can cross placenta during pregnancy; http://www1.folha.uol.com.br/internacional/en/scienceandhealth/2016/01/1731436 studyconfirmsthatzikaviruscancrossplacentaduringpregnancy.shtml. Last accessed January 31, 2016. [6]. Dupont-Rouzeyrol M, Biron A, O'Connor O, Huguon E, Descloux E. (2016). Infectious Zika viral particles in breastmilk. Lancet. 387(10023):1051. 
[7]. Fauci AS (2016) Morens DM (2016) Zika Virus in the Americas-yet another arbovirus threat. N Engl J Med 374: 601-604 3.

[8]. Gourinat AC, O'Connor O, Calvez E, Goarant C, Dupont-Rouzeyrol M. (2015). Detection of Zika virus in urine. Emerg Infect Dis. Jan21(1):84-6

[9]. Hearn PT, Atkinson B, Hewson R, Brooks T. (2014). Identification of the first case of imported Zika Fever to the UK: A novel sample type for diagnostic purposes and support for a potential nonvectorborne route of transmission. Am J Trop Med Hyg. 91(5):62-3. 71.

[10]. Lucey DR, Gostin LO (2016) The emerging Zika pandemic: enhancing preparedness. JAMA 315:865-866

[11]. Musso D, Nhan T, Robin E, Roche C, Bierlaire D, Zisou K, et al. (2014) Potential for Zika virus transmission through blood transfusion demonstrated during an outbreak in French Polynesia, November 2013 to February 2014. Euro Surveill 19(14):[pii=20761 p.]. Available from: http://www.eurosurveillance.org/ViewArticle.aspx?ArticleId=20761

[12]. Musso D, Roche C, Tu-Xuan N, Robin E, Teissier A, Cao-Lormeau VM.(2016) Detection of Zika virus in saliva. J ClinVirol. 68:53-5.

[13]. Maria A, Maquart M, Makinson A, Flusin O, Segondy M, Leparc-Goffart I, et al. (2016) Zika virus infections in three travellers returning from South America and the Caribbean respectively, to Montpellier, France, December 2015 to January 2016. Euro Surveill [Internet]. 2016; 21(6): [pii=30131 p.]. Available from: http://www.eurosurveillance.org/ViewArticle.aspx?ArticleId=21374

[14]. Musso D, Roche C, Robin E, Nhan T, Teissier A, Cao-Lormeau VM. (2015) Potential sexual transmission of Zika virus. Emerg Infect Dis.21(2):359-61.

[15]. Mansuy JM, Dutertre M, Mengelle C, Fourcade C, Marchou B, Delobel P, et al. (2016) Zika virus: high infectious viral load in semen, a new sexually transmitted pathogen? Lancet Infect Dis. EpubApr 16 (4): 405

[16]. Oehler E, Watrin L, Larre P et al (2014) Zika virus infection complicated by Guillain-Barre syndrome - case report, French Polynesia, December 2013. Eurosurveill Mar 6:19(9)

[17]. Regional Zika Epidemiological Update (Americas) 25 August 2016. www.paho.org/hq/index.php?option=com_content\&view=article\&id=11599\%3Aregional-

zikaepidemiological-update-americas\&catid=8424\%3Acontents\&Itemid=41691\&lang=en (accessed on 25-8-2016)

[18]. Rozé B, Najioullah F, Fergé J, Apetse K, Brouste Y, Cesaire R, et al. (2016). Zika virus detection in urine from patients with Guillain-Barré syndrome on Martinique, January 2016. Euro Surveill [Internet]. 2016; 21(9): [pii=30154 p.]. Available from: http://www.eurosurveillance.org/ViewArticle.aspx?ArticleId=21400

[19]. Sikka V, Chattu VK, Popli RK, Galwankar SC, et al. (2016). The emergence of Zika virus as a global health security threat: A review and a consensus statement of the INDUSEM Joint working Group (JWG). J Global Infect Dis 8:3-15

[20]. www.paho.org/hq/index.php?option=com_content\&view=article\&id=11640\&Itemid=135\&lang= en (accessed on 25 Aug 2016)

[21]. Zika virus updates from FDA, available at http://www.fda.gov/\%20EmergencyPreparedness/Counterterrorism/MedicalCountermeasures/MCMIss ues/ucm485199.htm (accessed on 1 May 2016)

[22]. Zika virus infection, Epidemiological Alert, PAHO/WHO 7 May 2015. 